\title{
BAHASA DAN BUDAYA MARITIM: IDENTITAS DAN PEMERKAYA BUDAYA BANGSA
}

\author{
Oktavianus \\ Fakultas Ilmu Budaya Universitas Andalas Padang \\ okv_26@yahoo.com
}

\begin{abstract}
Abstrak
Indonesia memiliki wilayah lebih kurang 1,9 juta mil persegi dengan jumlah pulau 17.508, 770 suku bangsa dan 726 bahasa (Tempo,co, 27 November 2017). Wilayah yang terdiri dari 17.508 pulau itu - yang disebut dengan NKRI dipersatukan oleh laut. Luasnya wilayah NKRI yang didiami oleh beragam suku dengan bahasa lokal yang berbedabeda merupakan suatu kekayaan dan keunikan yang dimiliki oleh bangsa Indonesia yang harus dijaga, dirawat dan dipertahankan. Sehubungan dengan itu, tulisan ini merupakan suatu upaya untuk menelaah bagaimana bahasa dan budaya maritim menjadi identitas dan pemerkaya budaya bangsa dalam hal ini bangsa Indonesia. Kajian dilakukan dari sudut pandang hubungan bahasa dengan budaya (Kramsch, 1998; Duranti, 2000). Data untuk keperluan kajian ini adalah penggunaan bahasa yang terkait dengan kelautan. Hasil kajian menunjukkan bahwa budaya maritim memberikan sumbangan yang sangat besar bagai pengembangan dan pemerkaya budaya bangsa (Indonesia). Leksikon-leksikon dan ungkapan kemaritiman tidak hanya dipakai dilingkungan kelautan tetapi juga digunakan dalam berbagai ranah pertuturan.
\end{abstract}

Kata kunci: bahasa, budaya maritim, leksikon dan ungkapan.

\section{PENDAHULUAN}

Manusia adalah makhluk terbaik yang dianugerahi dengan akal, pikiran, kelengkapan dan kesempurnaan fisik. Lebih dari itu, manusia juga dilengkapi dengan kemampuan berbahasa yang melebihi makhluk-makhluk lainnya di muka bumi ini. Belum ada makhluk di muka bumi ini yang memiliki kemampuan komunikasi melebihi manusia. Fromkin (2000) menyatakan bahwa bahasa hanya dianugerahkan kepada manusia dan bahasa itu membuat manusia menjadi manusia. Bahasa memiliki peran penting dan strategis dalam kehidupan manusia. Bila kita cermati secara mendalam, ada empat peran utama bahasa dalam kehidupan manusia. Keempat peran itu adalah sebagai alat komunikasi dalam arti luas, penamaan (naming) dan pelabelan (labeling), pengembangan budaya, dan penyimpan nilai.

Pertama, bahasa berperan sebagai alat komunikasi dalam arti luas. Manusia mengkomunikasikan segala keinginan, gagasan, apa yang dirasakan, apa yang tidak disukai, citacitanya, hasil ciptaan dan kreatifitasnya dengan menggunakan bahasa. Di samping itu, manusia juga mengkomunikasikan identitas budayanya melalui bahasa (Kramsch, 1998). Pada dasarnya, semua aktifitas manusia dilakukan dengan bahasa (Oktavianus, 2013). Seiring dengan kemajuan teknologi dan kompleksitas kehidupan manusia, pola-pola komunikasi sangat berkembang. Disain bahasa yang digunakan juga beragam. Komunikasi dapat dilakukan secara bertatap muka dalam jarak dekat dan jarak jauh. Komunikasi bahkan juga dapat dilakukan tanpa kehadiran lawan tutur.

Kedua, penamaan (naming) dan pelabelan (labelling) adalah peran utama lainnya dari bahasa manusia. Manusia mempunyai nama dan label. Bahkan manusia bisa memiliki lebih dari satu nama dan label. Makhluk-makhluk lainnya juga punya nama dan label. Segala aktifitas manusia juga diberi nama dan label. Nama dan label adalah sebagai penanda dan pengkategori. Betapa sulitnya komunikasi manusia tanpa kehadiran bahasa sebagai nama dan label berkaitan dengan segala sesuatu yang akan dikomunikasikannya. Betapa rumitnya kehidupan manusia tanpa kehadiran bahasa sebagai nama dan label terkait dengan segala sesuatu yang ada di sekelilingnya.

Ketiga, peran lainnya dari bahasa manusia adalah sebagai alat pengembangan budaya. Pada saat ini, kemajuan teknologi dan semakin tingginya mobilitas manusia membuat pergerakan manusia dan budayanya dari suatu tempat ke tempat lainnya tidak bisa dibendung. Produk-produk budaya dan industri suatu negara dengan mudah dapat ditemukan pada negara lainnya. Bahasa adalah 
bagian dari kebudayaan manusia. Jika kita berpegang kepada konsep ini, maka bahasa manusia di berbagai belahan dunia telah menjelajahi belahan dunia lainnya. Di ruang-ruang publik di seluruh dunia, bahasa Inggris sangat mudah ditemukan. Bahasa Inggris tidak hanya digunakan sebagai nama dan label produk yang berasal dari negara yang bahasa aslinya adalah bahasa Inggris tetapi juga digunakan sebagai nama dan label dari produk hampir setiap negara di dunia. Ini berarti bahwa bahasa Inggris sebagai budaya Inggris menempel ke budaya-budaya lainnya di seluruh dunia.

Keempat, bahasa juga berperan sebagai penyimpan dan penyebarluasan nilai. Nilai adalah elemen penting dalam kehidupan manusia. Nilai adalah norma atau batasan tentang sesuatu yang baik dan buruk, sesuatu yang berterima dan tidak berterima, pantas dan tidak pantas dalam kehidupan manusia. Nilai-nilai itu tersimpan dalam bahasa. Nilai-nilai itu diungkapkan dengan berbagai bentuk kalimat yang dikemas sedemikian rupa dalam bentuk berbagai jenis ungkapan dan peribahasa.

Bertolak dari keempat peran bahasa sebagaimana dikemukakan di atas, tulisan ini merupakan suatu upaya untuk melakukan pencermatan awal perihal hubungan bahasa dengan salah satu sisi budaya manusia yaitu budaya maritim. Bahasa dan budaya maritim sebagai identitas dan pemerkaya budaya bangsa dilihat dari keempat peran bahasa sebagaimana dikemukakan di atas yaitu bahasa sebagai alat komunikasi, bahasa sebagai penamaan dan pelabelan, bahasa sebagai pengembangan kebudayaan, dan bahasa sebagai penyimpan dan penyebarluasan nilai.

\section{Bahasa dan Kebudayaan}

Para linguis telah merumuskan pengertian bahasa manusia dari sudut pandang yang tidak selalu persis sama. Bila kita lihat secara lebih komprehensif, bahasa adalah bunyi-bunyi yang diproduksi oleh alat ucap manusia atau ide dan gagasan yang dituliskan pada berbagai medium dalam keadaan sadar, bersistem, bermakna, bernilai, berideologi, dipahami bersama oleh masyarakat penutur atau pengguna bahasa itu serta orang lain yang mempelajarinya. Kadar kebahasaan sebuah kata, kalimat atau ujaran sangat ditentukan oleh kebersisteman, kebermaknaan, kebernilaian serta keberideologian sebuah kata, kalimat atau ujaran yang digunakan oleh penutur bahasa itu. Kebersisteman, kebermaknaan, kebernilaian, dan keberideologian sebuah kata, kalimat atau ujaran adalah cerminan budaya penuturnya.

Berbicara mengenai kebudayaan kelompok penutur suatu bahasa tentu sangatlah kompleks. Edward B. Tylor, seorang antropolog Inggris, mengemukakan bahwa kebudayaan adalah keseluruhan aspek kehidupan manusia yang mencakup sistem pengetahuan, kepercayaan, kesenian, moral, hukum, adat-istiadat, sistem bahasa dan kemampuan-kemampuan lainnya yang diperoleh oleh suatu kelompok masyarakat. Koentjaraningrat (1993) mengemukakan bahwa kebudayaan adalah segala sesuatu yang berkaitan dengan budi dan akal pikiran. Konsep ini melahirkan kebudayaan dalam bentuk kebudayaan berwujud benda ciptaan, kebudayaan tak benda.

Bahasa dan kebudayaan dalam arti luas saling terkait satu sama lain. Ada tujuh unsur kebudayaan yang dianggap berlaku secara umum yaitu sistem pengetahuan, sistem bahasa, sistem organisasi sosial, sistem mata pencarian, sistem peralatan, sistem religi dan kepercayaan, serta sistem kesenian. Ketujuh unsur kebudayaan ini diyakini dimiliki oleh setiap kelompok suku. Di antara ketujuh itu, bahasa membungkus dan merepresentasikan enam yang lainnya. Sistem pengetahuan, sistem organisasi sosial, sistem mata pencarian, sistem peralatan, sistem religi dan kepercayaan, dan sistem kesenian dibangun, dikembangkan dan disebarluaskan melalui bahasa. Kramsch (1998:3) menyatakan bahwa language expresses, embodies, and symbolizes cultural reality. Bahasa berperan ganda. Bahasa berfungsi sebagai alat komunikasi dan yang dikemukasikan adalah kebudayaan masyarakat penuturnya (Bonvillain, 1997). Selanjutnya, Duranti (2000) menyebutkan enam hal terkait dengan kebudayaan dalam hubungannya dengan bahasa yaitu (1) kebudayaan sebagai pembeda antara manusia dengan hewan; (2) kebudayaan sebagai pengetahuan; (3) kebudayaan sebagai komunikasi dan cara pandang terhadap alam; (4) kebudayaan sebagai mediasi antara manusia dan lingkungannya; (5) kebudayaan sebagai sistem praktek dalam berbagai aspek kehidupan; dan (6) kebudayaan sebaga sistem partisipasi. Pada keenam hal itu, bahasa sangat berperan baik sebagai pembeda maupun sebagai penggerak. 


\section{Bahasa, Budaya Maritim dan Identitas Bangsa}

Seperti halnya manusia dan makhlukmakhluk lainnya, bahasa tumbuh. Bahasa berkembang lalu kemudian sebagiannya mengalami kepunahan. Bahasa tentu sangatlah berwarna-warni. Himpunan kosa kata dan kalimat yang digunakan dalam berbagai ranah pertuturan berasal dari lingkungan terdekat penuturnya. Kosa kata itu dapat berasal dari nama-nama benda dan aktivitas yang ada di sekelilingnya dan aktivitas yang dilakukan. Orang-orang yang tinggal di kawasan pesisir, di pantai-pantai, orang-orang yang bergelut dengan laut dengan segala aktivitasnya tentulah akan memiliki corak dan warna bahasa tersendiri. Nama-nama benda, peralatan, aneka jenis ikan, konsep dan ide tentang kelautan tentulah sangat mewarnai bahasa orang yang tinggal di pesisir dan mereka-mereka yang beraktivitas di laut. Tentang ini hipotesis SapirWhorf bahkan telah menyebutkan bahwa bahasa mendeterminasi cara berpikir penuturnya karena lingkungan pertuturan juga berbeda-beda dari satu penutur ke penutur lainnya. Penutur bahasa yang bermukim di kawasan pesisir tentu akan memiliki pola-pola dan warna bahasa yang berbeda dengan penutur yang bertempat tinggal di dataran tinggi.

Dua kata dalam bahasa Indonesia yang digunakan untuk menamai segala sesuatu yang terkait dengan kelautan adalah maritim dan bahari. Maritim berasal dari bahasa latin, mare dan bahari berasal dari bahasa Arab, bahrum. Keduanya memiliki titik temu pada medan makna yaitu segala sesuatu yang berkenaan dengan kelautan. Hal-hal yang berkaitan dengan kelautan tentulah sangat kompleks. Lingkungan laut memiliki ciri khasnya sendiri yang berbeda dengan darat. Laut kaya dengan flora dan fauna air. Kekayaan sumber daya alam yang ada di laut memicu timbulnya berbagai aktivitas di laut. Laut berfungsi sebagai jalur transportasi antar pulau. Laut adalah juga tempat bermain dan berekreasi.

Jika kebudayaan dikatakan sebagai segala sesuatu yang berkaitan dengan budi dan akal pikiran, maka budaya maritim adalah pemberdayaan budi dan akal pikiran untuk menata keseluruhan aspek kehidupan manusia melalui pemanfaatan semua hal yang terkait dengan kelautan. Karena lingkungan laut memiliki ciri khasnya sendiri, maka cara penataan keseluruhan aspek kehidupan manusia yang bermukim di kawasan pesisir, yang beraktivitas di laut, dan yang bermain di laut tentulah akan memperlihatkan ciri khasnya sendiri pula. Hal itu salah satunya dapat diamati melalui bahasa yang mereka gunakan.

\section{Bahasa sebagai alat komunikasi dalam masyrakat maritim}

Sebagaimana dikemukakan di atas, salah satu peran bahasa adalah sebagai alat komunikasi. Manusia hidup dan bermukim pada tempat yang berbeda-beda. Perbedaan lingkungan fisik tempat tinggal mereka berpengaruh kepada bahasa yang digunakan. Bagi masyarakat yang tinggal di kawasan pesisir dan yang beraktivitas di laut, kondisi geografis, cuaca, iklim dan tingkat kerumitan beraktivitas mempengaruhi pola-pola dan corak bahasa mereka. Fajrie (2017) mencatat bahwa gaya komunikasi masyarakat Pesisir Wedung Jawa Tengah terkesan kasar dan keras. Pada hal sebenarnya, mereka sudah mengikuti pola-pola pertuturan yang bernuasa berisi kesantunan. Pengamatan dan diskusi yang dilakukan terhadap nelayan di Pantai Purus Padang menunjukkan bahwa penggunaan bahasa bersifat kondisional. Kondisi cuaca, gelombang laut, area pemukiman, dan ruang komunikasi mempengaruhi psikologi para nelayan dalam bekerja. Faktor psikologis itu mewarnai bahasa mereka. Para nelayan cenderung menggunakan bahasa langsung, cepat dan lugas. Pada hal masyarakat Minangkabau adalah masyarakat yang berkencenderungan bertutur tidak langsung atau berkias. Metafora juga digunakan tetapi dalam konstruksi-konstruksi kalimat ringkas. Candra, dkk (2014) mencatat bahwa para nelayan di Kecamatan Sutera Pesisir Selatan Sumatera Barat bahkan menggunakan register-register yang mereka maknai sendiri yang mungkin tidak dipahami oleh orang lain. Dalam bahasa Minangkabau, bae 'pukul' tetapi di kalangan nelayan di Kecamatan Sutera, bae 'memasang jaring atau pukat'.

\section{Bahasa sebagai alat penamaan dan pelabelan dalam masyarakat maritim}

Kekayaan budaya masyarakat maritim dapat diamati dari banyaknya sumber daya alam yang ada di sekeliling mereka. Untuk memudahkan penataan dan pengelolaannya, bahasa sangat berperan dalam penamaan dan pelabelan. Namanama flora dan fauna air, aktivitas, peralatan, sifat dan ciri-ciri flora dan fauna air, aktivitas dan peralatan mencerminkan kekayaan budaya maritim yang dapat dibaca melalui bahasa yang digunakan. 
Indonesia sebagai negara maritim dengan luas wilayah lebih kurang 1,9 juta mil persegi dengan jumlah pulau 17.508, 770 suku bangsa dan 726 bahasa diyakini memiliki nama flora dan fauna air, aktivitas, peralatan, dan segala sesuatu yang bersangkutan dengan kemaritiman yang berbedabeda satu sama lain.

\section{Bahasa sebagai alat penyebarluasan kebudayaan dalam masyarakat maritim}

Bahasa selain sebagai alat komunikasi, penamaan dan pelabelan juga berperan sebagai alat penyebarluasan kebudayaan. Yang dimaksud dengan penyebarluasan kebudayaan adalah pemindahan ide, gagasan, dan pola-pola perilaku dari satu kelompok masyarakat kepada kelompok lainnya. Cara-cara berbahasa dan bertingkah laku masyarakat yang tinggal dan bermukim di kawasan pesisir pindah dan ditiru oleh masyarakat yang tidak tinggal atau bermukim di kawasan pesisir. Ada ungkapan-ungkapan yang muncul dan digunakan di kawasan pesisir pada awalnya, tetapi kemudian ungkapan itu dipakai secara luas dalam masyarakat sekalipun mereka tidak tinggal di kawasan pesisir. Berikut ini adalah beberapa contoh ungkapan dengan leksikon kelautan.

(1) Dalam laut dapat diduga, dalam hati siapa tahu

(2) Lautan sakti, rantau bertuah

(3) Kalau kail panjang sejengkal janganlah laut hendak diduga

(4) Garam di laut, asam di gunung, bertemu dalam belanga

(5) Asam di darat, ikan di laut, bertemu dalam belanga

(6) Lautan kalau ditimba kering jua

(7) Laut mana yang tak berombak, bumi mana yang tak berhujan

(8) Membuang garam ke laut

(9) Sekepal jadikan gunung, setitik jadikan lautan

(10) Sungguhpun kawat yang dibentuk, ikan di laut yang dihadang

\section{Bahasa sebagai alat penyimpan nilai dalam masyarakat maritim}

Nilai adalah kualitas atau ukuran baik dan buruk, pantas dan tidak pantas, berterima dan tidak berterima yang melekat pada sebuah objek, peristiwa, sikap dan perilaku. Sesuatu atau seseorang yang membawa kebaikan terhadap sesuatu atau seseorang yang lain, maka sesuatu atau seseorang itu disebut bernilai positif. Sesuatu atau seseorang yang dianggap membawa keburukan kepada sesuatu atau seseorang yang lain disebut bernilai negatif. Kalimat-kalimat yang dibentuk menjadi ungkapan dengan menggunakan leksikon kelautan dapat mengandung nilai-nilai positif yang dapat dijadikan pedoman dan peringatan dalam menghadapi berbagai dinamikan kehidupan. Hal itu dapat dilihat pada contohcontoh berikut.

(11) Dalam laut dapat diduga, dalam hati siapa tahu

(12) Lautan sakti, rantau bertuah

(13) Garam di laut, asam di gunung, bertemu dalam belanga

(14) Asam di darat, ikan di laut, bertemu dalam belanga

(15) Kalau kail panjang sejengkal janganlah laut hendak diduga

Dalam konteks pertuturan yang alamiah, ungkapan dengan menggunakan leksikon kelautan pada (11)(15) di atas memiliki nilai dasar yang amat penting bagi kehidupan manusia yaitu kehati-hatian dalam setiap kesempatan dan waktu. Kehati-hatian yang dimaksudkan di sini adalah kehati-hatian dalam bersikap dan memperlakukan orang lain. Ungkapan (15) kalua kail panjang sejengkal, janganlah laut hendak diduga mengandung nilai peringatan kepada manusia untuk mengukur kemampuan diri dalam mengejakan sesuatu. Berikut ini adalah salah satu contoh penggunaan ungkapan di atas dalam bahasa Minangkabau dalam suatu pertuturan yang alamiah dalam masyarakat.

(16) Kok baniek untuak pai marantau indak baa do. Tapi jan lupo lawik sati rantau batuah. Pandaipandai mamboakan diri kalau berniat pergi merantau, tidak apaapa, Tetapi jangan lupa bahwa lautan sakti rantau bertuah. Pandai-pandai menjaga diri'.

Sistem pengetahuan dan kepercayaan pada masyarakat maritim membawa mereka kepada pengalaman bahwa lautan itu sakti. Sistem pengetahuan dan kepercayaan yang dimiliki oleh 
masyarakat di perantauan membawa mereka kepada pengalaman bahwa rantau itu bertuah.

Nilai budaya dalam ungkapan yang dibentuk dengan leksikon kelautan juga sangat bervariasi. Nilai-nilai itu mengatur keseluruhan aspek kehidupan manusia. Nilai-nilai itu dapat pula dicermati pada contoh berikut.

(17) Lautan kalau ditimba kering jua

(18) Laut mana yang tak berombak, bumi mana yang tak berhujan

(19) Membuang garam ke laut

(20) Sekepal jadikan gunung, setitik jadikan lautan

(21) Sungguhpun kawat yang dibentuk, ikan di laut yang dihadang

Dengan tambahan-tambahan konstruksi sintaksis pada bagian-bagian tertentu dan dalam konteks pertuturan yang alamiah, ungkapan-ungkapan di atas dapat mengandung nilai yang berisi peringatan kepada manusia untuk berperilaku sederhana dan dapat mengekang hawa nafsu, bersikap sabar dan kuat karena kehidupan tidak dapat dilepaskan dari berbagai persoalan, menghindari pekerjaan yang sia-sia, menghargai dan memberdayakan sesuatu sekecil apapun. Contoh-contoh di atas adalah ungkapan yang terkait dengan kelautan tetapi dipakai secara luas dalam berbagai konteks pertuturan.

\section{Bahasa dan Budaya Maritim sebagai Pemerkaya Budaya Bangsa}

Bagaimana bahasa dan budaya maritim dapat memperkaya budaya bangsa ? Bila dicermati lebih dalam, bahasa dan budaya maritim sangat memperkaya budaya Indonesia. Dalam hal menangkap ikan sebagai sistem mata pencarian, sebagai contoh, aktivitasnya bergerak dari hulu sampai ke hilir. Banyak pihak terlibat. Mereka adalah penyedia kapal dan pembuat kapal dengan segala ikutannya, para nelayan, pembeli dan pengolah ikan. Dari sisi penyedia dan pembuat kapal, mereka harus memiliki sistem pengetahuan tentang perkapalan untuk nelayan seperti jenis bahan baku, kekuatan, disain, model dan ukuran kapal. Setiap suku di Indonesia ternyata memiliki nama-nama khas daerahnya untuk nama kapal tradisional penangkap ikan sebagai berikut.

$\begin{array}{lll}(22) & \text { PATORANI } & \text { Makasar } \\ (23) & \text { LAMBO } & \text { Mandar } \\ (24) & \text { JUKUNG } & \text { Jawa } \\ (25) & \text { PINISI } & \text { Bugis }\end{array}$

Diyakini pula bahwa suku-suku lainnya di Indonesia yang belum disebutkan di sini juga memiliki nama-nama perahu atau kapal tradisional penangkap ikan yang khas budaya setempat yang disesuaikan pula dengan sistem pengetahuan masyarakat setempat.

Selanjutnya, dari sisi nelayan, mereka harus memiliki sistem pengetahuan tentang pengoperasian kapal. Nelayan harus memiliki pengetahuan tentang musim, cuaca dan sifat-sifat ikan. Nelayan harus memiliki pengetahuan tentang lingkungan laut yang disukai ikan sehingga para nelayan mudah menangkap ikan dengan jumlah banyak. Nelayan harus memiliki pengetahuan tentang cara penyimpanan ikan di laut jika tidak cepat dibawa ke darat. Setelah dibawa ke darat, ikan berpindah tangan dari nelayan ke pembeli atau pengumpul untuk selanjutnya dioleh menjadi aneka masakan ikan. Semua pihak yang bersentuhan dengan aktivitas penangkapan ikan sebagai sistem mata pencarian sebagaimana disebutkan di atas harus cermat, teliti, tangguh, ulet, berani, sabar, bersih, jujur dan kreatif.

\section{PENUTUP}

Sebagai catatan akhir tulisan ini, bahasa dan budaya maritim sangat mewarnai budaya Indonesia. Hal ini dapat dilihat dari leksikonleksikon dan ungkapan-ungkapan kelautan yang dipakai pada berbagai ranah pertuturan. Indonesia disebut sebagai negara maritim tidak hanya berdasarkan pertimbangan letak wilayah secara geografis sebagai negara kepulauan yang diselingi oleh laut tetapi juga secara linguistik bertolak dari banyaknya leksikon dan ungkapan yang dibentuk dari segala sesuatu yang terkiat dengan kelautan.

\section{DAFTAR PUSTAKA}

Bonvillain, Nancy. 1997. Language, Culture and Communication : The Meaning of Message. New Jersey : Prentice-Hall, Inc.

Candra, Devi Mai, Syofyani dan Gusneti. 2014. "Register Bahasa Nelayan di Kecamatan Suter Kabupaten Pesisir Selatan: Suatu Tinjauan Sosiolinguistik. 
Duranti, A. 2000. Linguistic Anthropology. Cambridge: Cambridge University Press.

Fromkim, Rodman \& Hyams. 2003. Introduction to Language. London: Harcourt Brace Jovanovich.

Fajrie, Mahfudlah. 2017. "Gaya Komunikasi Masyarakat Pesisir Wedung Jawa Tengah".
Artikel dalam Interdisciplinenary Journal of Communication. Vol.2. No. 1 tahun 2017.

Koentjaraningrat. 1993. Kebudayaan, Mentalitas dan Pembangunan. Jakarta: Gramedia.

Kramsh, Claire. 1998. Language and Culture. Oxford: Oxford University Press. 